\title{
A Study of Digital Interactive Technology and Design Mode Promoting the Learners' Metacognitive Experience in Smart Education
}

\author{
Tao Liu and Haihao Zheng
}

\begin{abstract}
The effectiveness of learners' learning in smart education is largely improved by combined with digital interactive technology and design recent years. However, most traditional smart education ignore the importance of improving learners' metacognition experience by digital interactive technology and design. This paper focuses on the research of digital interactive technology promoting teaching reform to inspire the learners' metacognition experience, and interactive design mode inspiring the development of smart education platform. Digital interactive technology + interactive design mode + smart education has become an important trend of smart education reform.
\end{abstract}

Index Terms-Digital interactive technology, interactive design mode, smart education.

\section{INTRODUCTION}

With the development of digital interactive technologies such as virtual reality and artificial intelligence, the education environment has been greatly changed, and the relationship between learners and learning platform has been unprecedented reshaped. New digital interactive technologies are gradually infiltrating into all aspects of education. The deep integration of digital interactive technology and the education field improves the experience of learners greatly.

Generally speaking, the most important teaching evaluation index is the degree of knowledge transfer. However, with the development of digital interactive technology and the deepening of teaching ideas, the evaluation index is extended to the effect of learning experience. Positive learning experience can improve the learning efficiency. We should make full use of digital interactive technology to construct a diversified teaching environment and efficient teaching mode of smart education. Therefore, as an education with more interactive possibilities, smart education is attracting more and more attention from educational practitioners and researchers. It has become an inevitable trend of educational development in the information age to lead the innovative development of educational informatization by smart education and thus to promote educational reform [1].

This study explores the role of digital interaction

Manuscript received January 5, 2021; revised June 6, 2021.

Tao Liu is with Art Education Center, Northwest Polytechnic University, Xi'an, China (e-mail: $122151381 @$ qq.com).

Haihao Zheng is with School of Journalism and communication, Shaanxi Normal University, Xi'an, China. technology and design in improving metacognitive experience in smart education in the context of digital era. That is, this study explores how smart education uses digital interactive technology to promote the development of learners' metacognitive experience.

\section{SMart Education AND Metacognitive EvPERIENCE IMPROVEMENT}

"Smart education" is proposed by IBM. "Smart" here is not what we usually think of as "human wisdom" [2]. Smart education refers to knowledge construction activities characterized by decentralized learning resources, learner-centered learning, community collaboration through digital interactive technology and design, and learning experience construction in virtual environment [3].

In the context of smart education, the improvement of metacognitive experience is profoundly impacted on the learning effect and efficiency. Different researchers cut in from different perspectives, and the representative views are as follows. Jason Tan and Gautam Biswas made analysis from the role of feedback in preparation for future Learning. He believed that artificial intelligence can provide effective feedback information to online learners by simulating the thinking process of human brain, and metacognition plays an important role in the cultivation of learners' cognitive ability [4].

Professor Ekaterina also studies the function of metacognition in network Learning environment. He designed the framework of metacognition and information feedback in smart education [5].

Professor Eduardo believed that the metacognitive experience could adjust learning effect. He proposed the technology that redefines the way in which feedback is conceived and managed, enabling students, classmates and teachers to employ new channels of communication for real-time or deferred dialogue and promoting the metacognitive experience that are capable of improving or enhancing learning [6].

\section{A. Connotation of Smart Education}

Smart education is a kind of educational behavior with high learning experience, high content adaptability and high teaching efficiency provided by schools, regions or countries. It can use modern science and technology to provide a series of differentiated support and on-demand services for students, teachers and parents, etc. It can comprehensively collect and utilize the status data of participant groups and the data of education and teaching process to promote equity, 
continuously improve performance and foster educational excellence[7].

The society today is no longer the digital era dominated by Ethernet and LAN, but the I era based on the Internet. The characteristics of the era of smart education are concentrated in five aspects, which are referred to as" 5I", namely integration, intelligent, interactive ,internet and information [8].All five of these aspects are closely related to digital interactive technology and design. In other words, digital interactive technology and design can realize the characteristics of smart education.

Smart education combines traditional classroom teaching with online teaching, and online teaching can deepen, widen, intellectualize and entertain the traditional learning process. The application of digital interactive technology can not only arouse learners' interest in learning, but also deepen their learning process and effectively improve their learning efficiency.

\section{B. Composition of Metacognitive Experience}

The composition of metacognitive experience includes learners' concentration, interest, confidence and satisfaction [9], as shown in Table 1 below. Smart education explores the promotion of metacognitive experience under the background of "Internet +" era. It will awaken smart learning environment vitality and guide learners' growth, and enable learners to create their own study system, so as to ultimately achieve the goal of promotion metacognitive experience and learning efficiency.

TABLE I: THE COMPOSITION AND DESCRIPTION OF METACOGNITIVE EXPERIENCE

\begin{tabular}{ll}
\hline $\begin{array}{l}\text { Composition of } \\
\text { Metacognitive } \\
\text { Experience }\end{array}$ & EXPERIENCE \\
\hline Concentration & $\begin{array}{l}\text { The degree to which the learner's attention is } \\
\text { drawn to the content of the learning }\end{array}$ \\
\hline Interest & $\begin{array}{l}\text { The degree to which learners' learning goals } \\
\text { and needs are in line with the content involved } \\
\text { in the learning process }\end{array}$ \\
\hline Confidence & $\begin{array}{l}\text { The degree to which learners believe they can } \\
\text { perform well in the learning process or achieve } \\
\text { desired goals }\end{array}$ \\
\hline Satisfaction & $\begin{array}{l}\text { The degree to which the learner feels satisfied } \\
\text { with the learning process }\end{array}$ \\
\hline \hline
\end{tabular}

\section{1) Metacognitive experience: Concentration}

Concentration is one of the components of metacognitive experience. Concentration refers to the degree to which the learner's attention is attracted by the content of the study. Learners' concentration level is indeed uneven. Digital interactive technology and design in smart education will have a positive impact on deep learning. Attention is the window of learning, the sunlight of knowledge will not come in without it. Attention is also critical for learners. The poor academic record of learners may be related to the instability, inconcentration and unreasonable distribution of attention. There was an experiment by asking testees to recite the text, to evaluate the relationship between concentration and learning efficiency and finally conclude that the concentration has positive effects on learning efficiency. When the testees were highly attentive, they only had to read it nine times to reach the level of recitation. And the same text, when were distracted, the testees took 100 times to remember. Concentration, therefore, is the gateway to cognitive and intellectual activity.

\section{2) Metacognitive experience: Interest}

Interest is the best teacher. Once learners' learning goals and needs are consistent with the depth of the content involved in the learning process and then learners' interest in learning will be stimulated. Interest in learning is essential for every learner to have great achievement in studying. Now in the environment of exam-oriented education, heavy homework, profound and boring academic problems make many learners lose interest in learning, which also makes our ability gradually decline, contrary to the core literacy advocated. Therefore, it is very important to cultivate students' interest in learning. With the support of modern information technology, it is necessary to actively explore the application of informatization in smart education platform, and carry out flipped teaching reform to stimulate learners' interest in learning and improve the teaching effect in smart education.

\section{3) Metacognitive experience: Confidence}

Strong confidence occurs when learners believe that they can perform well in the learning process or achieve the desired goals. This confidence is crucial in the closed loop of the learning ecology of smart education. Only with confidence in learning can we have the power to drive autonomous learning and open the interface to complete knowledge transmission under the smart learning environment. The author believes that learners' confidence construction is very consistent with the "possible self" in self-schema theory. Markus believed that self-schema was a cognitive summary of the cognitive structure of the self and the possible self was an element related to the individual's potential ability and future evaluation [10].

\section{4) Metacognitive experience: Satisfaction}

Satisfaction refers to the degree to which learners are satisfied with the learning process. The possible self includes the ideal self which one hopes to become, such as the successful self, the respected self and so on. The possible self provides orientation guidance for the next action, and establishes a more obvious behavioral correlation between the internalization and externalization of the individual. When positive guidance occurs, there will be a positive possible self in the self-schema (i.e. the person presents the state of being eager to try), and a negative possible self (i.e. the person presents the state of being fearful) in the self-schema, until a certain moment when the positive self overcomes the negative self. The positive self has many stimuli, such as rewards, applause, praise, etc., and the more detailed the expression of these stimuli, the greater the role of self-schema adjustment. Smart education needs to provide such positive incentives to stimulate learners' self-confidence.

\section{RELATIONSHIP BETWEEN DIGITAL INTERACTIVE TECHNOLOGY AND METACOGNITIVE EXPERIENCE}

The above contents have a very good role in promoting our 
understanding of metacognitive experience in smart education. At present, there are two main aspects of problems need to be solved urgently in smart education: Firstly, what changes have taken place in learning activities with the application and development of digital interactive technology. Secondly, how to further break the bondage of time and space, construct knowledge connection at all times and develop students' comprehensive ability through digital interactive technology.

The development stages of the interactive technology mainly use different key skills, so that learners' metacognitive experience can be promoted by using different interactive technologies. Digital interactive technology focus on the key skills in VR,MR,Immersive3-D and AI, as shown in Table 2 below .If the positive experience of learners cannot be stimulated and learners cannot get the information and process of smart learning, smart education system cannot individually guide learners according to their actual learning conditions. Therefore, the effect of digital interactive technology must be intuitive and visible to learners.

TABLE II: The Key TECHNOLOGY AND MAIN CONTENT OF DEVELOPMENT STAGE OF THE INTERACTIVE ENVIRONMENT

\begin{tabular}{|c|c|c|}
\hline $\begin{array}{l}\text { The development } \\
\text { stage of the } \\
\text { interactive } \\
\text { environment }\end{array}$ & Key technology & Main content \\
\hline Primary stage & $\begin{array}{l}\text { Virtual reality } \\
\text { desktop }\end{array}$ & $\begin{array}{l}\text { The user interacts with the } \\
\text { virtual human using a specific } \\
\text { computer host and a monitor } \\
\text { with a mouse and keyboard }\end{array}$ \\
\hline Second stage & Mixed reality & $\begin{array}{l}\text { Using large-screen displays, } \\
\text { rear-projection screens and } \\
\text { head-mounted displays with } \\
\text { user motion tracking devices } \\
\text { and other changing display } \\
\text { methods, the real world and } \\
\text { virtual world are mixed to } \\
\text { give users a strong sense of } \\
\text { presence and immersion }\end{array}$ \\
\hline The third stage & Immersive3-D & $\begin{array}{l}\text { Virtual human can come to } \\
\text { the real world from the virtual } \\
\text { space to fully interact and } \\
\text { communicate with users }\end{array}$ \\
\hline Fourth stage & $\begin{array}{l}\text { Human-computer } \\
\text { interaction }\end{array}$ & $\begin{array}{l}\text { Future technology can allow } \\
\text { users to remotely interact with } \\
\text { the environment through their } \\
\text { senses }\end{array}$ \\
\hline
\end{tabular}

\section{A. Concentration and Virtual Reality (VR) Technology}

The teaching environment of smart education system connects the virtual and real space, which provides more possibilities and convenience for the development of teaching interaction. It emphasizes that in the field of smart education, the characteristics of timeliness, convenience, interestingness and interaction of VR technology are used to quickly detect the knowledge level of learners in order to promote the knowledge construction and problem solving of learners individually and collectively, and enhance the learning engagement of learners, that is, the ability of concentration.

\section{B. Interest and Mixed Reality (MR) Technology}

In order to further stimulate the interest of learners in learning, we need to strengthen the accumulation and research of digital interactive technology, from which we can analyze the deep relationship between learners' metacognitive experience and digital interactive design, find out the key factors that stimulate learners' interest in learning, and promote the wide application of digital interactive technology and design in the field of education. In smart education, MR environment is a computer - supported learning environment constructed by MR technology. In this environment, various objects from the real world and the virtual world are integrated into a single learning process. The smart learning environment with MR as the key technology is a continuous system from a real reality environment to a virtual reality environment. It is the fusion body of augmented reality environment and augmented virtual environment, and has the function of supporting embodied interaction. In smart education, the embodied learning environment constructed based on MR technology enables learners to use their own bodies to carry out various metacognitive activities, thus promoting their inetrest in scientific learning.

\section{Confidence and Immersive 3-D Technology}

With the help of immersive 3-D technology, through the computer connected to the software and hardware equipment, vivid, image, intuitive, and virtual reality situation of various knowledge scientifically abstract into concrete, static to dynamic, create a good learning atmosphere, stock up students' confidence in knowledge learning, and make their thinking began to active, fully ready to devote the education process of preparation, from the heart is willing to learn new knowledge, master new knowledge by smart education system. In the smart education system, learners have the confidence to become the master of learning, carry out active learning, actively explore the learning content with the help of immersive 3-D technology, independently arrange the learning time and progress, and actively form a cooperative teaching mechanism of mutual assistance with other learners and educators.

\section{Satisfaction and Artificial Intelligence (AI) Technology}

Artificial Intelligence can create a smarter environment for teachers and enable them to invest more support for learners with difficulties. The AI technology could create virtual teaching assistants. Assistants have more time focus on learners' guidance and one-to-one communication. In some countries, the smart education platform has begun to use AI assistants to provide learners with the best learning assistance. In addition, computer-aided learning creates alternatives that support learners' metacognitive experience with digital and artificial intelligence technologies. Artificial Intelligence can help to draw individual learning plans and tracks, strengths and weaknesses as well as learning preferences and activities of each learner. This can stimulate the satisfaction in metacognitive experience of learners well and thus improve the learning effect.

To sum up, the promotion of metacognitive experience in smart education is defined as the follows: In the context of 
smart learning, on the premise of rational using of digital interactive technology, learners are guided to learn actively and study effectively. There is a continuous and dynamic correlation between digital interaction technology and learners' metacognitive experience.

In a specific practice, the author mainly combines the four elements of metacognitive experience and the development stages of the interactive technology in smart education. About learners' metacognitive experience, more than half of them express that they are gradually finding a method of excitation suitable for their own learning characteristics. However, digital interactive technology' s help is still needed in the process of motivating learners' concentration, interest, confidence and satisfaction. Smart education with the help of digital interactive technology, through the computer connected to the software and hardware equipment, vivid, image, intuitive, virtual reality of various feedback learning situation scientifically, turn abstract into concrete, static to dynamic, create a good learning atmosphere, stimulate students "self" is likely, an aim to realize individual learning classification, fully prepared to devote to study, from the heart is willing to learn new knowledge, master new knowledge by wisdom education system.

\section{Digital Interactive Design Mode And METACOGNITVE EXPERIENCE}

At present, the digital interactive design mode of smart education has not yet formed a uniform mode which take the metacognitive experience of learners as the standard. Recent years, many scholars in the field of smart education and digital interactive technology have proposed a series of research works to innovate the interaction design mode according to their personal understanding and practice. Zhao developed a design mode based on the essence of knowledge and education with phenomenological methodology [11]. Scholars have paid much attention to the smart education and the interactive technology, but they have little research on how to build the design mode to promote the integration of digital interactive technology and smart education. Based on the main content described above, guided by interactive design and focused on learners' interactive experience, this study explores the interactive design mode of smart education. This mode will give a new explanation to four elements of design, including concept design, architectural design, interaction design and interface design, as is shown in Fig. 1.

The process of digital interactive design mode includes:

Concept design: Concept design is mainly designed to achieve the ideal state of learners' interactive experience according to the metacognitive experience of learners, including learners' concentration, interest, confidence and satisfaction;

Architecture design: It is designed from learners, teaching management and data management, which interact and correlate with each other to generate requests and responses;

Interaction design: Interaction design takes interaction technology as the principle and emphasizes unique,certainty,relevance, story,credibility,realizability,emo tional and spatiality of design. The design of interaction types, forms and degrees is guided by eight design principles and combined with digital interaction technology;

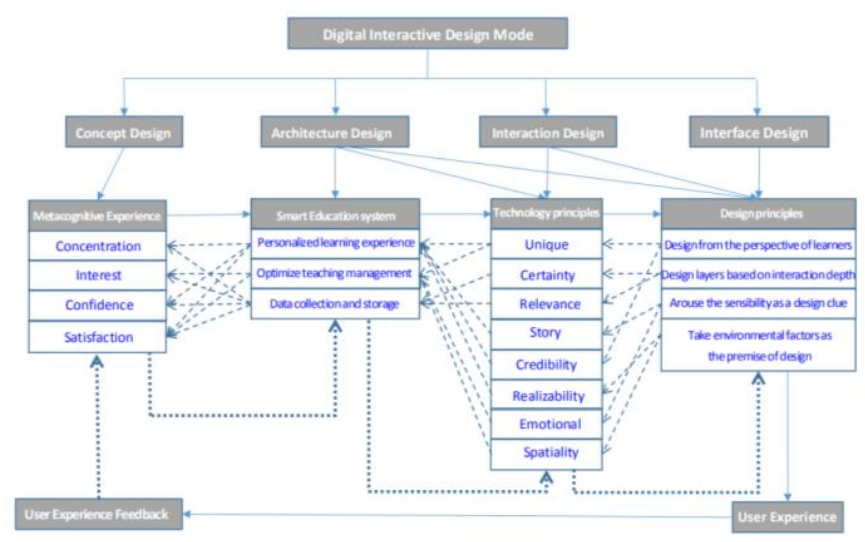

Fig. 1. The digital interactive experience design mode.

Interface design: Interface design visually wrap the given interaction, providing the learner with the interface of the interaction and the state of the response. It includes the following design principles, design from the perspective of learners, design layers based on interaction depth, arousing the sensibility as a design clue and taking environmental factors as the premise of design;

User Experience: Test and evaluate the user experience;

User experience feedback: User experience feedback sends experience information back to conceptual design to evaluate the usability and accuracy of conceptual design, and then loops back into interactive experience design mode to adjust expand the design.

\section{CONCLUSION}

This paper mainly discusses how the application and development of digital interactive technology and design can improve the environment of smart education, how to build a new educational model, and how to promote learners' metacognitive experience. In the future, due to changes of interactive technology and design mode, teachers' and learners' cognition will change, and the direction and focus of our scientific research will also change fundamentally. The use of digital interactive technology means to analyze learning situation, promote the metacognition experience of learners, so as to achieve the improvement of learners' core learning capacity, has the role that other teaching means cannot replace. The research results of digital interactive technology and design mode are applied in the process of education to promote the working efficiency of smart education and produce new teaching mode. In the digital era, we should make full use of the convenience brought by digital interactive technology and interactive experience design mode, which are innovative to improve efficiency on learning.

\section{CONFLICT OF INTEREST}

The authors declared that they have no conflicts of interest to this work.

We declare that we do not have any commercial or associative interest that represents a conflict of interest in connection with the work submitted. 


\section{AUTHOR CONTRIBUTIONS}

Tao Liu contributed to the conception of the study; Haihao Zheng contributed significantly to analysis and manuscript preparation.

\section{REFERENCES}

[1] Z. T. Zhu, "A new realm of education informatization," Research on Audiovisual Education, vol. 1, pp. 5-13.

[2] L. Chen, "Origin of smart education," Research on Audiovisual Education, vol. 1, pp. 23-31.

[3] Z. X. Zhong and Q. Zhang, "Discussing distributed learning," Research on Foreign Educational, vol. 1, pp. 65-72.

[4] J. Tan and G. Biswas, The Role of Feedback in Preparation for Future Learning, Springer-Verlag Berlin Heidelberg, vol. 4, pp. 101-105.

[5] E. Vasilyeva, M. Pechenizkiy, and P. Bra, Adaptation of Elaborated Feedback in e-Learning, Springer-Verlag Berlin Heidelberg, vol. 4, pp. 36-59.

[6] G.-J. Eduardo, Feedback and Self-Regulated Learning: How Feedback Can Contribute to IncreaseStudents' Autonomy as Learners, Springer International Publishing, vol. 4, pp. 49-53.

[7] R. H. Huang, "Three states of education: Environment, mode and system," Education Informatization in China, vol. 1, pp. 3-11.

[8] X. L. Zhong, "Analyze the framework of intelligent education system from nine aspects," Education Informatization in China, vol. 1, pp. 4-8.

[9] J. M. Keller, Motivational Design for Learning and Performance: The ARCS Model Approach, America, New York:Springer, vol. 1, pp. 68-74.

[10] H. Markus and P. Nurius, "Possible selves," American Psychologist, vol. 1, p. 41.
[11] H. L. Zhao, "Theoretical analysis on the construction of experiential learning model in ubiquitous technological environment," Journal of Distance Education, vol. 2, pp. 21-26.

Copyright $\odot 2021$ by the authors. This is an open access article distributed under the Creative Commons Attribution License which permits unrestricted use, distribution, and reproduction in any medium, provided the original work is properly cited (CC BY 4.0).

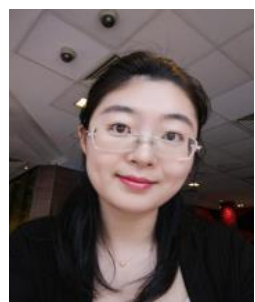

Tao Liu was born on September 15, 1984. She is a doctoral student majoring in digital media art at Communication University of China, director of Animation and Digital Media Art Committee of Chinese Academy of Film and Television, and associate professor of Art Education Center of Northwestern Polytechnical University. Her research fields include intelligent media development and intelligent education, the integration of digital media technology and art design.

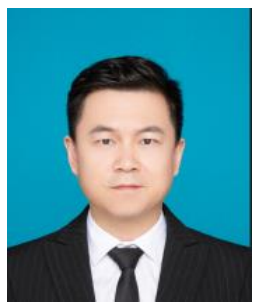

Haihao Zheng was born on May 10, 1984. He is a doctor of digital media art from Communication University of China, an expert of China Microbial Science and Technology Industry Doctoral Academician Association, and an associate professor of School of Journalism and Communication, Shaanxi Normal University. His research fields include digital media art, financial media. 